\title{
In vitro evaluation of photoprotective potential of the different solvent extracts of Graptophyllum pictum leaves
}

\author{
Khor Poh-Yen $^{1 *}$, Seow Lay-Jing ${ }^{1}$, Fatin Hanani ${ }^{2}$ \\ ${ }^{1}$ Senior Lectuer, Faculty Pharmacy and Health Sciences, UniKL RCMP, Jalan Greentown, 30450 Ipoh, Perak, Malaysia. \\ ${ }^{2}$ Student, Faculty Pharmacy and Health Sciences, UniKL RCMP, Jalan Greentown, 30450 Ipoh, Perak, Malaysia.
}

\begin{tabular}{|c|c|}
\hline ARTICLE INFO & ABSTRACT \\
\hline Article history: & \multirow{5}{*}{$\begin{array}{l}\text { Natural substances extracted from plants have been gaining attraction as protective agents due to their safety and } \\
\text { responsible for multiple biological effects on skins. The present work evaluates the photoprotective potential of } \\
\text { different solvent extracts of Graptophyllum pictum (G pictum) leaves, and the comparison of its Sun Protection } \\
\text { Factor (SPF) value against photo-stability and thermal-stability under a } 21 \text {-day of storage process. Preliminary } \\
\text { phytochemical screening was also performed. The dried powdered leaves were extracted by cold maceration } \\
\text { method, using five different solvent, i.e. methanol, ethanol, chloroform, ethyl acetate and hexane. The SPF of } \\
\text { all extracts were analyzed by ultraviolet (UV) spectrophometry. The SPF results of the five types of extracts } \\
\text { were found to have significant differences (P < } 0.001) \text {. Methanol extract displayed the highest SPF value } \\
\text { ( } 15.303 \pm 0.045 \text { ), while the lowest SPF value was showed by ethyl acetate extract. SPF reductions of all extracts } \\
\text { under sun exposure condition were higher compared to the extracts placed in dark conditions at room } \\
\text { temperature. As compared, the ethanol extract displayed better chemical and thermo-stability with higher in } \\
\text { vitro SPF at } 200 \mu \mathrm{g} / \mathrm{ml} \text {. These findings suggested that ethanol was the solvent of choice for yielding high levels } \\
\text { of photoprotective ingredients from } G \text {. pictum which can be used to formulate effective sunscreen preparations. }\end{array}$} \\
\hline Received on: $13 / 08 / 2017$ & \\
\hline Accepted on: $15 / 10 / 2017$ & \\
\hline Available online: $28 / 01 / 2018$ & \\
\hline $\begin{array}{l}\text { Key words: } \\
\text { Solanum sisymbriifolium, } \\
\text { Solanaceae, antinociceptive, } \\
\text { medicinal plant, pain. }\end{array}$ & \\
\hline
\end{tabular}

\section{INTRODUCTION}

Efficacy of sunscreen products is historically assessed through the determination of the so-called SPF, which is defined as the ultraviolet (UV) energy required to produce a minimal erythema dose (MED) on a protected skin versus the UV energy required to produce an MED on an unprotected skin. It is a measurement accepted worldwide to indicate how many times longer a person wearing sun protection in the sun can withstand without getting burned as opposed to not wearing any sun protection at all (Mbanga et al., 2015; Wagemaker et al.,2011). The UV light is classified into three major regions: UV-A (320 $400 \mathrm{~nm})$, UV-B (290-320 nm) and UV-C (200-290 nm). UV-C is most biologically damaging, but it gets effectively filtered by the ozone layer before reaching earth. Both UV-A and UV-B are

* Corresponding Author

Email: pykhor@ @nikl.edu.my not completely filtered out by the ozone layer and are responsible for the damage due to sunburn and pyrimidine dimers (Napagoda et al., 2016; Singh and Sharma, 2016).UV-B is approximately 1000 times more effective than UV-A in inducing erythema, most sunscreens contain compounds which absorb radiations in the UVB region (Shenoy et al., 2010; Van et al., 2017). The application of the sunscreen products that contain UV absorbing, reflecting or scattering active molecules is the most popular practice in the present day to reduce the amount of UV radiation penetrating the skin (Napagoda et al., 2016). Currently, the available sunscreen products with varying SPF often contain synthetic chemical compounds such as titanum oxide, benzophenone, bisdisolizole disodium (Fonseca, 2013) to cover a wide range spectrum of UV radiation protection. Unfortunately, these synthetic compounds are found to be potentially hazardous to health as they can cause skin diseases. Therefore, there is need to explore various natural and non-toxic sun protection properties from plant resources particularly to complement the current use of synthetic compounds. 
Graptophyllum pictum (G.pictum), or locally known as "Puding" or purple leave is a well-known traditional medicinal plant in Malaysia. The leaves of G.pictum are commonly consumed as culinary dishes by the Malay community (Singh et al., 2015a). Traditionally, G. pictum was consumed to enhance fertility, treat ulcers and constipation (Ministry of Health Republic of Indonesia, 2010). In vitro studies found that G. pictum is rich with phytochemical constituents and it possesses anti-oxidation (Singh et al., 2015b; Winata, 2011), antidiabetic (Ogbonnia et al., 2011), anti-implanation (Andrianto, 2015) and anti-plaque (Wahyuningtyas, 2005) properties. Though various pharmacognostical and phytochemical studies had been done on G. pictum, the leaf extract of this plant had notably not been previously assessed on the sun protective ability. Scientists believe that the chemical components on some plants, like anthocyanins, proanthocyanidin and carotenoids may act as a natural "sunscreen," protecting the cells from too much light (Koracand Khambhoja, 2011; Stahl and Sies, 2007). In such, the leaves of $G$. pictum with strong brown and purple color are suspected to have high sun protective properties (Saewan and Jimtaisong, 2013).

According to the literature review, around 50 plant species from various plant parts that had been tested for in vitro SPF and the sun protection efficacy was found be in the range of $0.1-39$ at the concentration of $200-1000 \mu \mathrm{g} / \mathrm{ml}$ (Gajardo et al., 2016; Gonçalves et al., 2015). It was noted that various plant parts were extracted only with either methanol or ethanol while other organic solvents which could affect extractable the sun protective ingredients were not well explored. In addition, to the best of our knowledge, only two studies had successfully been investigated and reported to date on the photo-stability and thermal-stability of plant extracts (Fonseca, 2013; Napagoda et al., 2016). The present work was aimed on evaluation of photoprotective potential of various extracts of $G$. pictum leaves, and to compare the SPF values from each extract against photo-stability and thermalstability under a 21-day of storage process.

\section{MATERIALS AND METHODS}

\section{Plant Material}

Fresh leaves of $G$. pictum were collected from Kuala Pilah district which is located in the southern Malaysian state of Negeri Sembilan. The plant material was identified by Dr Fatimah Mohamed from Universiti Pendidikan Sultan Idris, Tanjung Malim, Perak. The plant material was thoroughly cleaned and dried under shade for four days. Dried plants were powdered using an electrical grinder (Panasonic Mixer Grinder MX-AC400W). The powder was then stored in an airtight sample bottle for further analysis.

\section{Preparation of Extracts}

The dried powdered of the G. pictum leaves (10 grams per solvent) were extracted by cold maceration in methanol, ethanol, hexane, ethyl acetate, and chloroform respectively for three days. The extracts were concentrated under reduced pressure using a rotary evaporator until dryness to yield five different solvent extracts.

\section{Preliminary phytochemicals screening}

The phytochemical screening of each extract $(1 \mathrm{~g} / \mathrm{mL}$ in mother solvent) was performed according to the standard phytochemical screening method (Prashant et al., 2011) and the observations were recorded.

\section{Determination of the in vitro Sun protection factor (SPF)}

The in vitro SPF was determined by following the modified spectrophotometric method (Fonseca, 2013). Each extract was diluted in the mother solvent respectively at a final concentration of $200 \mu \mathrm{l} / \mathrm{ml}$. The samples were placed in (i) dark conditions at room temperature $\left(27^{\circ} \mathrm{C}\right)$ and (ii) sunlight exposure at temperature higher than $27^{\circ} \mathrm{C}$. The measurement of SPF was evaluated at $7^{\text {th }}, 14^{\text {th }}$ and $21^{\text {st }}$ day interval period,by using UV spectrophotometry (Perkin-Elmer) from 290 to $320 \mathrm{~nm}$, with intervals of $5 \mathrm{~nm}$. The readings were taken in triplicate and the determinations were made at each point. The SPF was calculated according to the equation (1).

$$
\operatorname{SPF}=\mathrm{CF} \times \sum_{290}^{320} \mathrm{EE}(\lambda) \mathrm{xI}(\lambda) \mathrm{x} \operatorname{Abs}(\lambda)
$$

Where the obtained absorbance values between 290 and $320 \mathrm{~nm}$ were multiplied with the respective EE $(\lambda)$ values. Their summation was taken and multiplied with the correction factor (10) to obtain the SPF values. The data were expressed as \pm standard deviation. All data were analyzed statistically by the OneWay ANOVA and T-Test analyses to analyse SPF against various days of exposure. The analysis was performed using the statistical package for Social Sciences version 17.0 (a window software for data analysis) and the level of significance was set at $p=0.05$.

\section{RESULT AND DISCUSSION}

\section{Preliminary Phytochemical screening}

Preliminary phytochemical screening of the crude extracts of leaves of $G$. pictum revealed the presence of different kind of chemical groups as summarized in Table 1. Leaves of $G$. pictum had resulted in the identification of carbohydrate, flavonoids and alkaloids, for both methanol and ethanol extracts. Steroids and glycosides were found to be present in chloroform, ethyl acetate and hexane extracts. This result supplies the additional information as current literature only reports of phytochemical constituents from ethanol and petroleum ether extract (Singh et al., 2015a).However, negative results of phytochemical constituents were reported for hexane and ethyl acetate extract (Jiangseubchatveera et al., 2017). All types of solvent extractions gave negative of volatile oil indication. This being attributed to the very low composition of volatile oil in leaves, which is only extractable through distillation process (Jiangseubchatveera et al., 2015). 
Table 1: Phytochemical screening ofvarious extracts of G. pictum leaves.

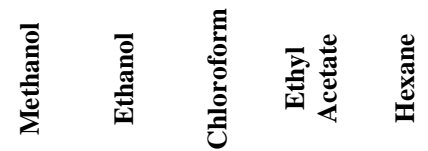

\begin{tabular}{lccccc}
\hline Alkaloid & & & & & \\
\hline Mayer test & + & + & - & - & - \\
Wagner test & + & + & - & - & - \\
\hline Carbohydrate & & & & & \\
\hline Molisch test & + & + & - & - & - \\
\hline Steroids & & & & & \\
\hline Liebermann-Burchard test & - & - & + & + & + \\
Salkowski & - & - & + & + & + \\
\hline Cardiac glycosides & & & & & \\
\hline Keller Killani's test & - & - & + & + & + \\
Baljet test & - & - & + & + & + \\
\hline Flavanoids & & & & & \\
\hline Ferric chloride test & + & + & - & - & - \\
Lead acetate test & + & + & - & - & - \\
\hline Volatile oil & & & & & \\
\hline Filter paper & - & - & - & - & - \\
NaOH & - & - & - & - & - \\
\hline Remarks: + presence, - absence & & & & &
\end{tabular}

Remarks: + presence, - absence.

The results of the evaluation of in vitro SPF of various extract of G. pictum leaves are shown in Table 2. All reported SPF results were found significantly different $(\mathrm{P}<0.001)$. Among the five extracts tested, methanol extract had displayed the highest SPF value as $15.303 \pm 0.045$. SPF values of ethanol and chloroform extract were $13.423 \pm 0.004$ and 13.181 \pm 0.008 , respectively. The ethyl acetate extract showed the lowest SPF value as $11.656 \pm 0.001$. SPF values of methanol and ethanol extract are comparatively higher than reported in previous studies (Costa et al., 2015; Gajardo, 2016; Gonçalves et al., 2015; Napagoda et al., 2016). Whereas, SPF value obtained from hexane, chloroform and ethyl acetate had never been reported before.

Table 2: SPF of various extracts of G. pictum leaves.

\begin{tabular}{ccc}
\hline Extracts & SPF & $P$-value \\
\hline Methanol & $15.300 \pm 0.005$ & \\
Ethanol & $13.423 \pm 0.004$ & \\
Chloroform & $13.181 \pm 0.008$ & 0.000 \\
Hexane & $12.777 \pm 0.001$ & \\
Ethyl acetate & $11.657 \pm 0.001$ & \\
\hline
\end{tabular}

According to the guidelines of international regulatory agencies, only SPF value equal or greater than 6 is suitable for use in cosmetic products (Costa et al., 2015). Hence, the results suggested that the $G$. pictum extract can be considered as a promising active ingredient because of its high SPF value in low concentration $(200 \mu \mathrm{g} / \mathrm{ml})$. If higher SPF is required for formulation, it can be achieved by reducing the dilution factor when preparing the G. pictum extract because SPF is found to be concentration-dependent (Costa et al., 2015). One of the most important factors affecting the extraction efficiency of bioactive compounds from plant materials and their consequent health benefits is the extraction solvent (Van et al., 2017). The better solubility of photo protective ingredient in ethanol and methanol can be attributed to its chemical structure of flavonoids and alkaloids. The characteristic conjugated system in these phytochemicals enables it to absorb high intensity of UV rays (Saewan and Jimtaisong, 2013), hence producing better SPF. The lower in vitro SPF readings in chloroform, hexane and ethyl acetate extracts is possibly due to the presence of steroids, cardiac glycoside and other non-tested secondary metabolites such as chlorophyll and carotenoid. The higher SPF value of chloroform extract may be attributed due to the higher concentration of photoprotective ingredient compared to hexane and ethyl acetate extracts. Although no specific literature is available on the correlation of these compounds to SPF, the common chemical feature of the steroid, cardiac glycoside structure with less number of carbon conjugated system is less capable of absorbing UV light.

\section{Determination of the in vitro Sun protection factor (SPF)}

The comparison of SPF values from different extracts of G. pictum leaves versus the storage period under room temperature and sunlight exposure were presented in Figure 1 and 2. In terms of thermal and photo stability, there is an overall consistent reduction in the sun protection capability of each extract from days 7,14 to 21 .

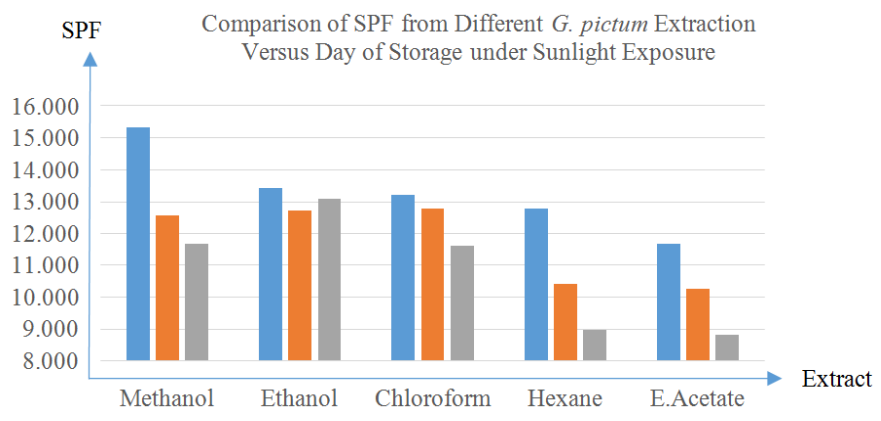

Fig. 1: Comparison of SPF from different G. pictum extracts versus day of Storage under sunlight exposure

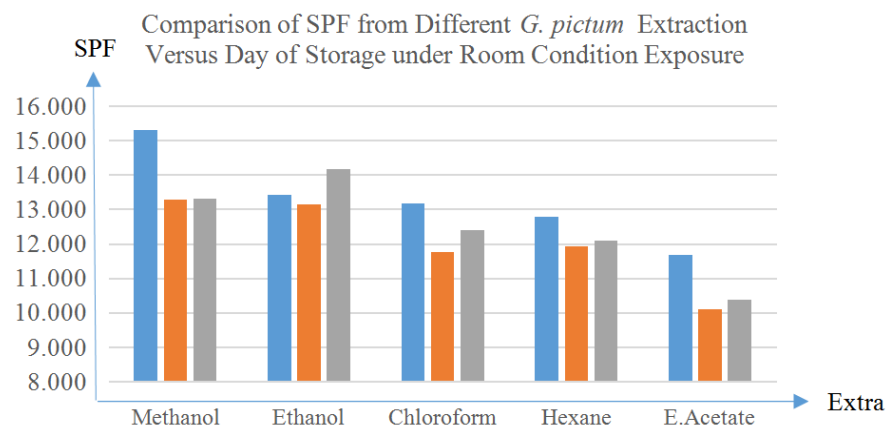

Fig. 2: Comparison of SPF from different G. pictum extracts versus Day of Storage under room condition exposure

The total percentage of reduction of SPF values from different extracts of $G$. pictum leaves under room condition and sunlight exposure were summarized in Table 3. 
Table 3: Comparison of total $\%$ reduction of SPF.

\begin{tabular}{|c|c|c|c|c|c|c|}
\hline Exposure & Day & Methanol & Ethanol & Chloroform & Hexane & EthylAcetate \\
\hline \multirow{4}{*}{ sunlight } & $7^{\text {the }}$ & $15.300 \pm 0.005$ & $13.423 \pm 0.004$ & $13.181 \pm 0.008$ & $12.777 \pm 0.001$ & $11.657 \pm 0.001$ \\
\hline & $14^{\text {th }}$ & $12.551 \pm 0.006$ & $12.697 \pm 0.010$ & $12.779 \pm 0.003$ & $10.384 \pm 0.008$ & $10.250 \pm 0.005$ \\
\hline & $21^{\text {st }}$ & $11.653 \pm 0.002$ & $13.080 \pm 0.035$ & $11.606 \pm 0.004$ & $8.968 \pm 0.004$ & $8.797 \pm 0.005$ \\
\hline & Reduction (\%) & $24 \%$ & $3 \%$ & $14 \%$ & $42 \%$ & $25 \%$ \\
\hline \multirow{4}{*}{ Room } & $7^{\text {th }}$ & $15.303 \pm 0.006$ & $13.423 \pm 0.000$ & $13.180 \pm 0.010$ & $12.780 \pm 0.005$ & $11.660 \pm 0.000$ \\
\hline & $14^{\text {th }}$ & $13.273 \pm 0.058$ & $13.137 \pm 0.006$ & $11.770 \pm 0.006$ & $11.933 \pm 0.006$ & $10.090 \pm 0.000$ \\
\hline & $21^{\text {st }}$ & $13.297 \pm 0.006$ & $14.160 \pm 0.006$ & $12.397 \pm 0.006$ & $12.087 \pm 0.000$ & $10.360 \pm 0.000$ \\
\hline & Difference $(\%)$ & $13 \%$ & $0 \%$ & $6 \%$ & $5 \%$ & $11 \%$ \\
\hline
\end{tabular}

The SPF reductions of all extracts under sun exposure condition were higher compared to the extracts placed in dark conditions at room temperature.

Heat and light acceleration induced conjugated a structural change, the degradation and oxidation stress of the extracted chemical constituents. However, without heat and UV exposure, the reduction of SPF was mainly caused by oxidation of a prolonged storage process.

Although all the extracts were found to have reduction in sun protective ability, ethanol extract was found to be the most stable sample in the 21-day storage duration. Table 3 showed that SPF of ethanol extract only reduced 3\% and $0 \%$ under sunlight exposure and room condition respectively. Hence, at $21^{\text {st }}$ day, the SPF of methanol extract was the highest in comparison to other extracts.

The stability of ethanol extract can be due to high polarity of ethanol solvent which capable of extracting broad polar and semi-polar constituents, and hence, the ability to produce a better sun protection coverage. Furthermore, the synergistic effect of various compounds is found capable of providing broader protection.

The good photoprotective potential was observed on ethanol extract of $G$. pictum leaves, however, they cannot be used as stand-alone photoprotective agent. In vitro SPF tests are usually served as a preliminary screening to choose the best extract. Further studies like antioxidant activity studies and in-vivo SPF testing are suggested. The photoprotective compounds in the leaves can be isolated and be used in formulations of natural sunscreen, as well as replacing the synthetic sunscreens.

\section{CONCLUSION}

This study indicated that the G. pictum leaves sun protective ability is well related to the choice of solvent extraction used. These findings suggested that ethanol was the solvent of choice for yielding high levels of photo-protective ingredients and better stability in 21-day storage condition, which can be used to formulate effective sunscreen preparations.

\section{ACKNOWLEDGEMENTS}

We are very grateful to laboratory Assistant in the Faculty Pharmacy and Health Sciences for their excellent assistance in making this research success. We also appreciated students who has assisted us in sample preparation and testing for the sample. A heartfelt appreciation is also due to Prof. Dr. Mohd Syafiq bin Abdullah who still remains as a source of strength and inspiration to this researcher.

\section{CONFLICT OF INTEREST}

The authors declare no conflict of interest.

\section{REFERENCES}

Andrianto D. 2015. Biochemical utilization of Indonesian forest biomass as antioxidant, antidiabetic, and antihyperlipidemic Agents Available at: https://www.ehime-u.ac.jp/data_paper/data_paper-7741 [Accessed 23 Jan 2017]

Costa SCC, Detoni CB, Branco CRC, Botura MB, Branco A. In vitrophotoprotective effects of Marcetiataxifoliaethanolic extract and its potential for sunscreen formulations. Brazilian Journal of Pharmacognocy, 2015; 25: 413-418.

Fonseca A. Determination of sun protection factor by UV-Vis spectrophotometry. Health Care : Current Reviews, 2013; 1: 1-4.

Gajardo S, Stowhas T, Salas F, Quispe C, Buc-calderon P, Benites J. Determination of sun protection factor and antioxidant properties of six Chilean Altiplano plants. Blacpma, 2016; 15: 352-363.

Gonçalves KM, Polonini HC, Viccini LF, Lyderson F, Antônio M, Brandão F, Rezende N, Raposo B. Assessment of the photoprotective activity of Lippia Species from Brazil and their use as single UV filters in sunscreens. Journal of Young Pharmacist, 2015; 7: 368-372.

Jiangseubchatveera N, Liawruangrath B, Liawruangrath $\mathrm{S}$, Teerawutgulrag A, Dammrong SJK, Stephen GP. The chemical constituents and the cytotoxicity, antioxidant and antibacterial activities of the essential oil of Graptophyllum pictum (L.) Griff. Journal of Essential Oil Bearing Plants, 2015; 18: 11-17.

Jiangseubchatveera $\mathrm{N}$, Liawruangrath $\mathrm{S}$, Teerawutgulrag A, Santiarworn D, Pyne SG, Liawruangrath B. Phytochemical screening, phenolic and flavonoid contents, antioxidant and cytotoxic activities of Graptophyllum pictum (L.) Griff. Chiang Mai Journal of Science,2017; 44: 193-202.

Korac RR, Khambholja KM. Potential of herbs in skin protection from ultraviolet radiation. Pharmacology Review, 2011; 5:164173.

Mbanga L, Mpiana PT, Mbala M, Ilinga L, Ngoy B, Mvingu K, Mulenga M. Comparative in vitro Sun Protection Factor (SPF) values of some herbal extracts found inKinshasa by Ultraviolet Spectrophotometry.Journal of Physical and Chemical Sciences, 2015; 2:1 6.

Ministry of Health Republic of Indonesia. Guidelines for the Use of Herbal Medicines in Family Health Care. 2010; 100.

Napagoda MT, Malkanthi BMAS, Abayawardana SAK, Qader MM, Jayasinghe L. Photoprotective potential in some medicinal plants used to treat skin diseases in Sri Lanka. BMC Complementary and Alternative Medicine, 2016; 16: 1-6.

Ogbonnia SO, Coker HAB, Ukpo GE. Blood glucose lowering effect of aqueous extract of Graptophyllum pictum (Linn) Griff. 
onalloxan-induced diabetic rats and its acute toxicity in mice. African Journal of Biotechnology, 2011; 10:1039-1043.

Prashant TB, Kumar MK, Gurpreet KHK. Phytochemical screening and extraction: A review. International Journal of Pharmacy and Pharmaceutical Science. 2011; 1: 98-106.

Saewan N, Jimtaisong A. Photoprotection of natural flavonoids. Journal of Applied Pharmaceutical Science, 2013;3:129-141.

Shenoy PA, Khot SS, Chavan MC, Takawale JV, Singh S. Study of sunscreen activity of aqueous, methanol and acetone extracts of leaves of Pongamia pinnata (L.) Pierre, Fabaceae. International Journal of Green Pharmacy, 2010; Oct-Dec: 270-274.

Singh P, Khosa RL, Mishra G, Jha KK. Pharmacognostical evaluation of aerial parts of Grapthophyllum pictum (L.) Griff. (Syn: Justica picta Linn.): A well-known folklore medicinal plant. Ancient Science of Life, 2015a; 34: 223-229.

Singh P, Khosa RL, Mishra G, Tahseen MA. A phytopharmacological review on Justicia picta (Acanthaceae): A wellknown tropical folklore medicinal plant. Journal of Coastal Life Medicine, 2015b; 3: 1000-1002.

Singh M, Sharma V. Spectrophotometric determination of Sun Protection Factor and antioxidant potential of an herbal mixture. British Biotecnology Journal, 2016; 10: 1-8.

Stahl W, Sies H. Carotenoids and flavonoids contribute to nutritional protection against skin damage from sunlight. Molecular Biotechnology,2007; 37: 26-30.
Van NT, Scarlett CJ, Bowyer MC, Ngo PD, Van VQ. Impact of different extraction solvents on bioactive compounds and antioxidant capacity from the Root of Salacia chinensis L. Journal of Food Quality, $2017 ; 2017: 1-8$.

Wagemaker TAL, Carvalho CRL, Maia NB, Baggio SR, Filho OG. Sun protection factor, content and composition of lipid fraction of green coffee beans. Industrial Crops and Products, 2011; 33:469-473.

Wahyuningtyas E. The Graptophyllum pictum extract effect on acrylic resin complete denture plaque growth.Dental Journal, 2005; 8:201204.

Winata H. 2011. Aktivitas Antioksidandan Kandungan Kimiawi Estrak Daun Wungu (Graptophyllum pictum L. Griff). Available at: http://repository.ipb.ac.id [Accessed 08 Dec 2016]

\section{How to cite this article:}

Poh-Yen K, Lay-Jing S, Hanani F. In vitro evaluation of photo protective potential of the different solvent extracts of Graptophyllum pictum leaves. J App Pharm Sci, 2018; 8 (01): 147151. 